\title{
Comparison of effects of intraoperative esmolol and ketamine infusion on acute postoperative pain after remifentanil-based anesthesia in patients undergoing laparoscopic cholecystectomy
}

\author{
Mi Hyeon Lee ${ }^{1}$, Mi Hwa Chung ${ }^{1}$, Cheol Sig Han ${ }^{1}$, Jeong Hyun Lee ${ }^{1}$, Young Ryong Choi ${ }^{1}$, Eun Mi Choi ${ }^{1}$, \\ Hyun Kyung Lim $^{2}$, and Young Duk Cha ${ }^{2}$ \\ Department of Anesthesiology and Pain Medicine, ${ }^{1}$ Kangnam Sacred Heart Hospital, Hallym University College of Medicine, Seoul, \\ ${ }^{2}$ Inha University College of Medicine, Incheon, Korea
}

Background: Remifentanil is a short-acting drug with a rapid onset that is useful in general anesthesia. Recently, however, it has been suggested that the use of opioids during surgery may cause opioid-induced hyperalgesia (OIH). Researchers have recently reported that esmolol, an ultra-short-acing $\beta_{1}$ receptor antagonist, reduces the postoperative requirement for morphine and provides more effective analgesia than the administration of remifentanil and ketamine. Hence, this study was conducted to determine whether esmolol reduces early postoperative pain in patients who are continuously infused with remifentanil for anesthesia during laparoscopic cholecystectomy.

Methods: Sixty patients scheduled to undergo laparoscopic cholecystectomy were randomly divided into three groups. Anesthesia was maintained with sevoflurane and $4 \mathrm{ng} / \mathrm{ml}$ (target-controlled infusion) of remifentanil in all patients. Esmolol ( $0.5 \mathrm{mg} / \mathrm{kg})$ was injected and followed with a continuous dosage of $10 \mu \mathrm{g} / \mathrm{kg} / \mathrm{min}$ in the esmolol group $(\mathrm{n}=20)$. Ketamine $(0.3 \mathrm{mg} / \mathrm{kg})$ was injected and followed with a continuous dosage of $3 \mu \mathrm{g} / \mathrm{kg} / \mathrm{min}$ in the ketamine group $(\mathrm{n}=20)$, while the control group was injected and infused with an equal amount of normal saline. Postoperative pain score (visual analog scale [VAS]) and analgesic requirements were compared for the first 6 hours of the postoperative period.

Results: The pain score (VAS) and fentanyl requirement for 15 minutes after surgery were lower in the esmolol and ketamine groups compared with the control group $(\mathrm{P}<0.05)$. There were no differences between the esmolol and ketamine groups.

Conclusions: Intraoperative esmolol infusion during laparoscopic cholecystectomy reduced opioid requirement and pain score (VAS) during the early postoperative period after remifentanil-based anesthesia. (Korean J Anesthesiol 2014; 66: 222-229)

Key Words: Esmolol, Hyperalgesia, Ketamine, Postoperative pain, Remifentanil, Sevoflurane.

Received: April 15, 2013. Revised: 1st, May 23, 2013; 2nd, June 25, 2013. Accepted: June 27, 2013.

Corresponding author: Eun Mi Choi, M.D., Department of Anesthesiology and Pain Medicine, Kangnam Sacred Heart Hospital, Hallym University College of Medicine, 948-1, Daerim 1-dong, Yeongdeungpo-gu, Seoul 150-950, Korea. Tel: 82-2-829-5230, Fax: 82-2-845-1571, E-mail: emchoi96@hanmail.net

() This is an open-access article distributed under the terms of the Creative Commons Attribution Non-Commercial License (http:// creativecommons.org/licenses/by-nc/3.0/), which permits unrestricted non-commercial use, distribution, and reproduction in any medium, provided the original work is properly cited. 


\section{Introduction}

Remifentanil is a short-acting, selective $\mu$-opioid agonist that has a rapid onset of action; it is used widely in surgery because the effect disappears quickly, even when the drug is continuously infused during surgery, and the risk of delayed postoperative awakening or ventilatory suppression is thus reduced [1]. Recently, however, it has been noted that the use of opioids during surgery can cause opioid-induced hyperalgesia $(\mathrm{OIH})$, making it difficult to control postoperative pain [2]. In addition, opioids with a rapid onset of action, such as remifentanil, may induce OIH more quickly and frequently [3]. OIH is caused by central sensitization through the activation of the N-methylD-aspartate (NMDA) receptor [4]. Central sensitization results when materials such as glutamate, aspartate, and substance $\mathrm{P}$ are emitted from the excitatory synapse membranes in the spinal dorsal horn, leading to a series of changes [1]. The emitted materials activate the postsynaptic NMDA receptors, resulting in increased intake of secondary messenger $\mathrm{Ca}^{2}$ and causing central sensitization [1]. Ketamine is a non-competitive NMDA receptor antagonist that prevents central sensitization by blocking excitatory amino acids such as glutamate from activating the NMDA receptor [5]. Various experimental studies have shown that low-dose ketamine obstructs central sensitization and is effective in preventing $\mathrm{OIH}$ [6,7]. Alternatively, beta-adrenergic blocking agents are reported to reduce the postoperative opioid requirement, which is considered an antinociceptive effect [811]. Esmolol is an ultra-short-acting cardioselective $\beta_{1}$ adrenergic receptor antagonist. A recent study reported that esmolol reduced the postoperative morphine requirement and provided more effective analgesia compared with coadministration of remifentanil-ketamine [12].

Hence, this study compared additional administration of esmolol with additional administration of ketamine in patients receiving a continuous infusion of remifentanil during laparoscopic cholecystectomy to examine whether esmolol reduces early postoperative pain after this method of anesthesia.

\section{Materials and Methods}

This research was conducted after receiving approval from the hospital's ethics committee. The research design was a prospective, observer-blinded, randomized, controlled study. Informed consent was obtained from all patients, and data were collected from May to October 2012. Sixty patients aged 2070 years and of American Society of Anesthesiologists physical status 1 or 2 scheduled for laparoscopic cholecystectomy under general anesthesia were selected as subjects. Patients with hepatic diseases, renal diseases, diabetes mellitus or cardiac diseases, recent administration of opioids or beta blockers, asthma, air- way hypersensitivity, diseases related to the airway, or allergies to drugs were excluded from the study. The patients were randomly assigned by a computer program to receive remifentanil and esmolol during surgery (esmolol group), remifentanil and ketamine (ketamine group), or remifentanil and normal saline (control group). A total of 3 medical staff members participated in the induction and maintenance of anesthesia and the postoperative evaluation. A single anesthesiologist, who participated in the research design but not in the postoperative evaluation, induced anesthesia. Anesthesia was maintained by another anesthesiologist who was unaware of the patient groupings, and postoperative evaluation was performed by a nurse who was also unaware of the patient groupings. Midazolam $2 \mathrm{mg}$ and glycopyrrolate $0.2 \mathrm{mg}$ were injected intramuscularly as premedication. After patients' arrival in the operating room, standardized monitoring equipment was attached to measure heart rate, blood pressure, oxygen saturation, and electrocardiography. Equipment was also attached to measure the BIS (Bispectral Index Monitor, Aspect Medical Systems, Inc., USA), and baseline figures for all measurements were obtained. Anesthesia induction was performed with propofol $(1.5 \mathrm{mg} / \mathrm{kg})$, and effect-site target concentration of remifentanil $4 \mathrm{ng} / \mathrm{ml}$ (target-controlled infusion, $4 \mathrm{ng} / \mathrm{ml}$ ) was infused using an Orchestra pump (Orchestra Infusion Workstation, Fresenius Vial, France). After the effectsite target concentration was reached, confirmation was made of lack of response to oral command and loss of the eyelid reflex. Then rocuronium $0.6 \mathrm{mg} / \mathrm{kg}$ was intravenously (IV) injected. When muscle relaxation was confirmed, tracheal intubation was performed. For the esmolol group, based on a precedent study [12], esmolol (0.5 mg/kg) was IV injected during anesthesia induction, and continuous infusion of esmolol $10 \mu \mathrm{g} / \mathrm{kg} / \mathrm{min}$ was performed during surgery. For the ketamine group, based on a precedent study [1], ketamine $(0.3 \mathrm{mg} / \mathrm{kg})$ was IV injected during anesthesia induction, and $3 \mu \mathrm{g} / \mathrm{kg} / \mathrm{min}$ was continuously infused during surgery. For the control group, the same amount of normal saline was administered once during anesthesia induction and continuously infused during surgery. Anesthesia was maintained with $1.5-2.0$ vol\% sevoflurane, with the effectsite target concentration of $4 \mathrm{ng} / \mathrm{ml}$ remifentanil in all groups. The depth of anesthesia was controlled to maintain a BIS value between 40-60. When anesthesia induction and maintenance set-up were completed, the anesthesiologist was replaced with another who was unaware of the patient groupings to continue maintenance of anesthesia according to protocol. Ephedrine was increased $4 \mathrm{mg}$ when blood pressure decreased more than $20 \%$ from baseline during surgery, and ephedrine $4 \mathrm{mg}$ or atropine 0.1 $\mathrm{mg} / \mathrm{kg}$ was IV injected when the heart rate was less than $45 \mathrm{bpm}$ or the mean arterial blood pressure was $55 \mathrm{mmHg}$ or lower. In addition, nicardipine $0.6 \mu \mathrm{g} / \mathrm{kg}$ was IV injected when blood pressure increased $20 \%$ or more from baseline. Any changes in 
patient status were immediately dealt with and recorded. Before suturing the operated area, fentanyl $1.5 \mu \mathrm{g} / \mathrm{kg}$ (to maximum 100 $\mu \mathrm{g})$, ketorolac tromethamine $30 \mathrm{mg}$, and 1 ampule ramosetron $(0.3 \mathrm{mg} / 2 \mathrm{ml} /$ ampule) were IV injected. After suturing the operated area, sevoflurane and remifentanil were stopped, and the infusions of esmolol, ketamine, and normal saline were also stopped. Glycopyrrolate $0.4 \mathrm{mg}$ and pyridostigmine $20 \mathrm{mg}$ were IV injected to reverse muscle relaxation, and manual ventilation was performed with $100 \%$ oxygen to maintain end tidal $\mathrm{CO}_{2}$ concentration at $35-45 \mathrm{mmHg}$. When a patient responded to an oral command and opened his or her eyes, and the tidal volume was appropriate (or there was sufficient antagonism), extubation was performed and the patient was moved to the recovery room. The patient's blood pressure, heart rate, hemodynamic changes in oxygen saturation and subsequent drug administration during surgery were recorded, as well as the total amount of remifentanil, esmolol, and ketamine used during surgery, the time taken from measurement of $0.3 \mathrm{vol} \%$ sevoflurane in patient expiration to patient awakening and extubation, and other actions that were taken.

For 1 hour after arriving in the recovery room, the hemodynamic thresholds of each patient were observed and recorded at 5 minute intervals. Pain score (visual analog scale [VAS]), $0=$ no pain, $10=$ most severe pain possible), postoperative nausea and vomiting, state of sedation, pain in the operated area, and other complications were evaluated immediately after recovery room arrival, then at 5 minutes, 15 minutes, 30 minutes, 45 minutes, and 60 minutes after arrival. When needed, medication was administered according to protocol, and the dose administered was recorded. When the pain score (VAS) was $>4$, IV fentanyl was administered with an initial dose of $50 \mu \mathrm{g}$, with subsequent doses of $25 \mu \mathrm{g}$ if the pain score (VAS) persisted $>4$. Additional analgesic was administered when necessary. Glycopyrrolate 0.2 mg was IV injected when the patient's heart rate was less than $50 \mathrm{bpm}$, and nicardipine $6 \mu \mathrm{g} / \mathrm{kg}$ was IV injected when systolic blood pressure was $180 \mathrm{mmHg}$ or higher or when diastolic blood pressure was $120 \mathrm{mmHg}$ or higher. When a patient's blood pressure decreased $20 \%$ or more from the threshold blood pressure, ephedrine was increased $4 \mathrm{mg}$ and IV injected. Antiemetics were administered when postoperative nausea or vomiting developed. Each patient was moved to the general ward after stabilizing. When patients were moved to the general ward from the recovery room, a ward nurse unaware of patient groupings observed and recorded the hemodynamic figures and pain score (VAS), nausea and vomiting, state of sedation, other complications, and type and amount of analgesic administered up until 6 hours after surgery. When the pain score (VAS) was $>4$, tramadol $50 \mathrm{mg} / 1 \mathrm{ml} /$ ampule was IV injected, and when the pain score (VAS) was still $>4$ after 30 minutes, additional analgesic was administered. One hour later, the pain was reevaluated, and further analgesic was administered when the pain score (VAS) remained $>4$. This process was repeated when patients complained of pain. Decisions regarding additional analgesic were made by the surgery department, and the type and amount of administered analgesic were recorded.

Statistical analysis was performed using SAS version 9.2 (SAS Institute Inc., Cary, NC, USA). The chi-square test and Fisher's exact test were performed for categorical variables, and parametric analysis of the ANOVA test and the non-parametric KruskalWallis test were performed for continuous variables. For repeatedly measured data, the ANOVA test and Kruskal-Wallis test not considering repeated measurement, and the linear mixed model considering repeated measurement, were performed. The results were expressed as the mean $\pm \mathrm{SD}$, and a $\mathrm{P}$ value of less than 0.05 was considered statistically significant. The primary outcome measure was the pain score (VAS) in the recovery room, and secondary outcome measurements were fentanyl consumption, occurrence of postoperative nausea and vomiting, and state of sedation during the research period. The sample size was based on a precedent study [13], where the mean difference

Table 1. Demographic, Surgical, and Anesthetic Characteristics

\begin{tabular}{|c|c|c|c|c|}
\hline & Esmolol $(n=20)$ & Ketamine $(\mathrm{n}=20)$ & Control $(\mathrm{n}=20)$ & P value \\
\hline Age (yr) & $51.9 \pm 14.1$ & $45.6 \pm 11.3$ & $43.2 \pm 12.3$ & 0.0861 \\
\hline $\operatorname{Sex}(M / F)$ & $10 / 10$ & $8 / 12$ & $8 / 12$ & 0.7622 \\
\hline Body mass index $\left(\mathrm{kg} / \mathrm{m}^{2}\right)$ & $25.2 \pm 2.7$ & $24.6 \pm 2.6$ & $23.4 \pm 3.1$ & 0.1234 \\
\hline Operation time (min) & $67.3 \pm 28.2$ & $78.0 \pm 27.5$ & $73.0 \pm 21.3$ & 0.4304 \\
\hline Anesthesia time (min) & $94.9 \pm 27.6$ & $100.0 \pm 27.3$ & $95.5 \pm 21.1$ & 0.7862 \\
\hline Total amount remifentanil during anesthesia $(\mu \mathrm{g})$ & $690.0 \pm 246.9$ & $797.5 \pm 239.2$ & $792.0 \pm 267.0$ & 0.3205 \\
\hline Total amount ketamine during anesthesia (mg) & - & $39.6 \pm 9.5$ & - & - \\
\hline Total amount esmolol during anesthesia (mg) & $93.6 \pm 29.0$ & - & - & - \\
\hline Sevo $0.3(\mathrm{~min})$ & $7.0 \pm 2.6$ & $5.8 \pm 2.5$ & $4.5 \pm 1.4$ & $0.0026^{*}$ \\
\hline
\end{tabular}

Values are presented as the mean \pm SD. Sevo $0.3(\mathrm{~min})$ is defined as the time taken from measuring 0.3 vol\% sevoflurane in patient expiration to patient awakening. No statistical differences were observed between the three groups $(\mathrm{P}>0.05)$. However, there was a difference between the three groups in the time taken from measuring 0.3 vol\% sevoflurane in patient expiration to patient awakening $(* \mathrm{P}=0.0026)$. The esmolol group took more time than the control group $(\mathrm{P}=0.006)$, while the ketamine group and the control group showed no significant difference $(\mathrm{P}=0.0927)$. 
Table 2. Intraoperative Variables in Each Group

\begin{tabular}{llccc}
\hline & Measured time & $\begin{array}{c}\text { Esmolol group } \\
(\mathrm{n}=20)\end{array}$ & $\begin{array}{c}\text { Ketamine group } \\
(\mathrm{n}=20)\end{array}$ & $\begin{array}{c}\text { Control group } \\
(\mathrm{n}=20)\end{array}$ \\
\hline MBP (mmHg) & Baseline & $96.15 \pm 15.13$ & $93.56 \pm 14.03$ & $93.23 \pm 14.04$ \\
& After intubation & $96.63 \pm 20.93$ & $76.67 \pm 15.16$ & $83.78 \pm 25.49$ \\
& Start of surgery & $80.98 \pm 13.34$ & $74.35 \pm 6.45$ & $76.45 \pm 7.41$ \\
& 20 min after incision & $87.60 \pm 13.69$ & $95.43 \pm 19.83$ & $91.90 \pm 13.78$ \\
ER (beats/min) & End of surgery & $104.12 \pm 17.53$ & $115.75 \pm 13.96$ & $108.70 \pm 14.70$ \\
& Baseline & $68.50 \pm 15.32$ & $67.75 \pm 10.67$ & $69.65 \pm 14.44$ \\
& After intubation & $75.40 \pm 13.04$ & $71.80 \pm 13.45$ & $77.55 \pm 22.24$ \\
Oxygen saturation (\%) & Start of surgery & $64.95 \pm 11.96$ & $62.95 \pm 9.17$ & $66.15 \pm 40.62$ \\
& 20 min after incision & $69.15 \pm 15.67$ & $69.40 \pm 11.46$ & $69.95 \pm 16.94$ \\
& End of surgery & $80.90 \pm 13.26$ & $79.90 \pm 10.97$ & $86.25 \pm 13.56$ \\
& Baseline & $96.45 \pm 1.85$ & $96.55 \pm 1.85$ & $96.40 \pm 1.67$ \\
& After intubation & $98.90 \pm 0.72$ & $99.05 \pm 0.76$ & $99.15 \pm 0.59$ \\
& Start of surgery & $98.90 \pm 0.79$ & $98.80 \pm 1.01$ & $99.10 \pm 0.91$ \\
& 20 min after incision & $99.20 \pm 0.69$ & $99.10 \pm 0.79$ & $99.25 \pm 0.72$ \\
& End of surgery & $99.55 \pm 0.51$ & $99.80 \pm 0.52$ & $99.15 \pm 1.46$ \\
\hline
\end{tabular}

Values are presented as the mean \pm SD. No statistical differences were observed between the three groups $(\mathrm{P}>0.05)$. MAP: mean arterial blood pressure, HR: heart rate.

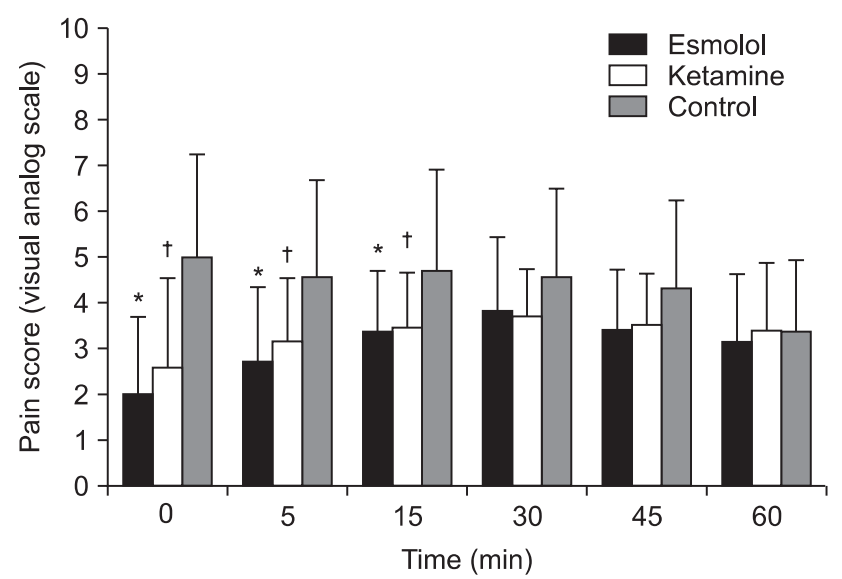

Fig. 1. Pain score (visual analog scale) measured for 1 hour in the recovery room. Data are the mean \pm SD. The esmolol group and the ketamine group appeared to have especially reduced scores compared with the control group for the first 15 minutes, with no differences between the esmolol and ketamine groups $\left(* \mathrm{P}<0.05,{ }^{\dagger} \mathrm{P}<0.05\right)$.

in pain score (VAS) between the ketamine group and the control group was hypothesized as 1.5 and the standard deviation as 1.5. The $\alpha$ value was calculated as 0.05 and test power ( $\beta$ value) as 0.8 . Twenty subjects were included in each group considering a $20 \%$ failure rate.

\section{Results}

Sixty patients were included in this study. Demographic data and characteristics of the surgery and anesthesia are shown in Table 1. There were no significant differences in demographic data between the three groups. In addition, there were no differ-

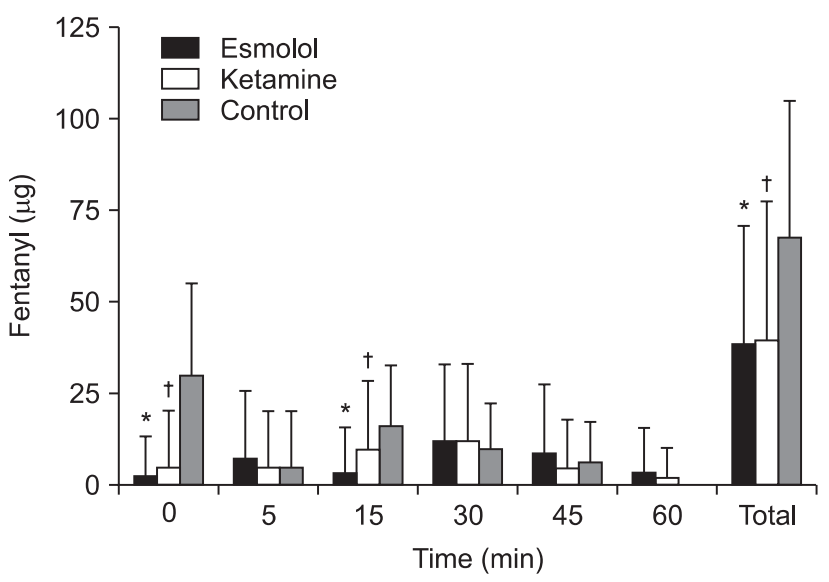

Fig. 2. Postoperative fentanyl requirement in the recovery room. Data are the mean \pm SD. The fentanyl requirement at 5 minutes and 15 minutes after surgery in the esmolol group and the ketamine group was less than in the control group, as was the total amount of fentanyl administered during the first hour after surgery in the recovery room $\left({ }^{*} \mathrm{P}<0.05,{ }^{\dagger} \mathrm{P}<0.05\right)$. There was no difference between the esmolol and ketamine groups.

ences observed in anesthesia time and surgery time. Intraoperative and postoperative administration of atropine, ephedrine, and nicardipine also showed no difference between the three groups. However, there was a difference between the three groups in the time taken from measuring $0.3 \mathrm{vol} \%$ sevoflurane in patient expiration to patient awakening $(\mathrm{P}=0.0026)$. The esmolol group took longer than the control group $(\mathrm{P}=0.006)$, while the ketamine group and the control group showed no significant difference $(\mathrm{P}=0.0927)$. Table 2 shows the blood pressure, heart rate, and oxygen saturation of patients during surgery. There were no differences between the three groups in 
these variables (Table 2). In addition, the continued monitoring of blood pressure, heart rate, and oxygen saturation until 6 hours after surgery showed no significant difference between the three groups $(\mathrm{P}>0.05)$.

Fig. 1 shows the mean pain score (VAS) measured during the first hour after surgery in the recovery room. The esmolol group and the ketamine group appeared to have particularly reduced scores compared with the control group for the first 15 minutes $(\mathrm{P}<0.05)$, with no differences between the esmolol and ketamine groups (Fig. 1). Fig. 2 shows the fentanyl requirement in the recovery room after surgery. The fentanyl requirement at 5 minutes and 15 minutes after surgery in the esmolol group and the ketamine group was less than the requirement in the control group, as was the total amount of fentanyl administered during the first hour after surgery in the recovery room $(P<0.05)$. There was no difference between the esmolol and ketamine groups.

The pain score (VAS) from 1 hour to 6 hours after surgery did not differ between the three groups (Fig. 3). Table 3 shows the total amount of administered analgesic from 1 hour after surgery. The total amount of administered analgesic from 1 hour after surgery did not differ between the three groups $(\mathrm{P}>0.05)$. None of the groups experienced nausea, vomiting, lethargy, or other complications in the recovery room after surgery.

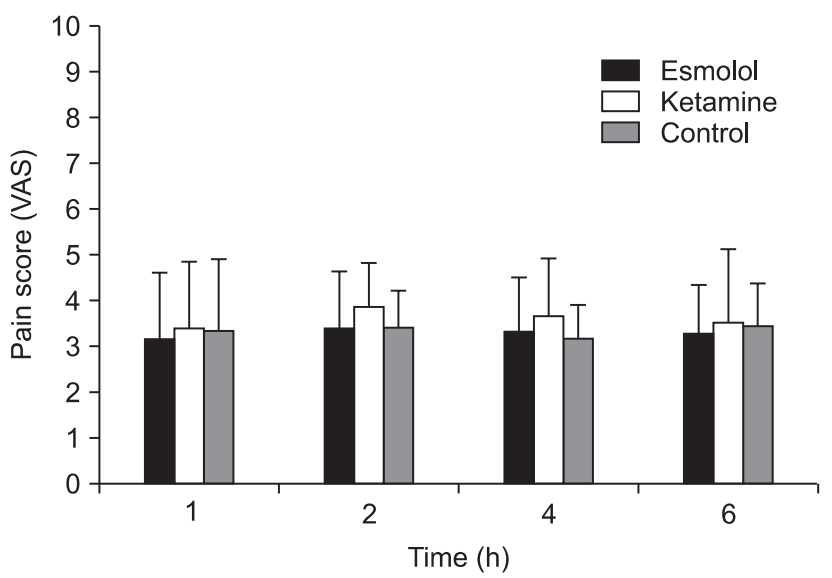

Fig. 3. Pain score (visual analog scale) from 1 hour to 6 hours after surgery. Data are the mean \pm SD. No statistical differences were observed between the three groups $(\mathrm{P}>0.05)$.

\section{Discussion}

In this study, pain score (VAS) were reduced for 15 minutes after surgery and fentanyl requirements were reduced in the esmolol group compared with a control group that received a continuous infusion of normal saline during laparoscopic cholecystectomy with remifentanil-based anesthesia. In addition, there appeared to be no difference in pain score (VAS) for 1 hour after surgery and fentanyl requirement between the esmolol group and a group continuously infused with low-dose ketamine, which is known for its effect in preventing $\mathrm{OIH}$.

This study was conducted with patients undergoing laparoscopic cholecystectomy, and all three groups were IV injected with a target-controlled infusion of remifentanil $4 \mathrm{ng} / \mathrm{ml}$. Although laparoscopic cholecystectomy is associated with a lesser degree of postoperative pain compared to open cholecystectomy, various methods of pain control are necessary due to pain in the surgical incision, visceral pain, and referred pain [14]. Among these methods, opioids have the advantage of blocking adverse reactions to strong external stimuli to stabilize patients' vital signs and reducing the amount of anesthetics used during surgery. However, opioids with long transit times are problematic because they can cause complications such as bradycardia, hypotension, delayed postoperative awakening, and ventilatory suppression [1]. Remifentanil is a potent, short-acting opioid with a rapid onset of action, and it has the advantage of effectively attenuating painful stimuli and unwanted cardiovascular effects during surgery [15]. In addition, because it has an anesthetic-sparing effect, it is known to enable rapid emergence after laparoscopic cholecystectomy [16]. However, some studies have reported that the use of remifentanil causes acute tolerance or hyperalgesia. In one study conducted with volunteers [17], capsaicin-induced hyperalgesia was enhanced $180 \%$ when 3-4 ng/ml of remifentanil was IV injected for 60-100 minutes. Another study reported that an effect-site target concentration of 3-4 $\mathrm{ng} / \mathrm{ml}$ remifentanil was sufficient to cause hyperalgesia [18], and Joly et al. [6] stated that it is important to decide on the appropriate dosage when infusing remifentanil during surgery. Although the mechanism by which remifentanil acts on NMDA is controversial, activation of NMDA receptors is known to play an important role in remifentanil-induced hyperalgesia [7].

Table 3. Total Amount of Administered Analgesic from One Hour after Surgery

\begin{tabular}{lcccc}
\hline & $\begin{array}{c}\text { Esmolol group } \\
(\mathrm{n}=20)\end{array}$ & $\begin{array}{c}\text { Ketamine group } \\
(\mathrm{n}=20)\end{array}$ & $\begin{array}{c}\text { Control group } \\
(\mathrm{n}=20)\end{array}$ & P value \\
\hline Total tramadol (mg) & $50(0,100)$ & $0(0,100)$ & $50(0,100)$ & 0.9726 \\
Total diclofenac (mg) & $0(0,0)$ & $0(0,90)$ & $0(0,90)$ & 0.3613 \\
Total ketorolac (mg) & $0(0,30)$ & $0(0,30)$ & $0(0,30)$ & 0.3341 \\
\hline
\end{tabular}

Values are presented as the median (min, max). No statistical differences were observed between the three groups $(\mathrm{P}>0.05)$. 
Ketamine is a NMDA receptor antagonist reported to modulate remifentanil-induced hyperalgesia $[1,19,20]$. In the present study, ketamine was continuously infused during surgery at a dosage reported effective by Hong et al. [1] (ketamine $0.3 \mathrm{mg} / \mathrm{kg}$ IV injected during anesthesia induction followed by continuous infusion of ketamine $3 \mu \mathrm{g} / \mathrm{kg} / \mathrm{min}$ ). The blood pressure, heart rate, and oxygen saturation during and after surgery did not show any differences in the ketamine group compared with the control group. In addition, no differences with the control group were observed in postoperative sedation, hallucinations, or complications such as postoperative nausea and vomiting (PONV). However, the pain score (VAS) was lower in the ketamine group than in the control group for 15 minutes after surgery, and the fentanyl requirement was reduced. There were no differences from 1 hour to 6 hours after surgery. Unlike these results, Hong et al. [1] reported that ketamine reduced the pain score (VAS) and PCA (Pain Management Provider, Abbott Laboratories, Chicago, USA) requirement for 180 minutes after surgery. This discrepancy is thought to be due to differences in the postoperative analgesics between the two studies, with each analgesic acting distinctively with the residual effects of ketamine.

Esmolol is an ultra-short-acting cardioselective $\beta_{1}$ adrenergic receptor antagonist used to weaken the stress response during surgery and to reduce unwanted perioperative hemodynamic changes [21]. Several reports state that administration of esmolol during surgery produces an opioid-sparing effect [11,22]. Collard et al. [22] reported that esmolol can replace intraoperative opioids and is associated with a reduction in postoperative fentanyl consumption. White et al. [11] reported that postoperative opioid requirement was reduced when esmolol was infused after the administration of fentanyl $1.5 \mu \mathrm{g} / \mathrm{kg}$ during induction in laparoscopic gynecology surgery. In addition, Chia et al. [10] reported that morphine consumption was reduced for 3 days after surgery when esmolol was continuously infused after administration of fentanyl $3 \mu \mathrm{g} / \mathrm{kg}$ during induction in females undergoing total abdominal hysterectomy. One study [12] reported that esmolol is not only effective in reducing postoperative morphine requirement but also more effective in postoperative analgesia than coadministration of ketamineremifentanil. However, these studies did not examine the effect of esmolol on acute postoperative pain after remifentanil-based anesthesia. In the present study, effect-site target-controlled infusion of intraoperative remifentanil $4 \mathrm{ng} / \mathrm{ml}$ was maintained while an esmolol dosage reported to be effective in a precedent study [12] was continuously infused to allow comparison with a control group. There were no differences in intraoperative hemodynamic changes, postoperative sedation, PONV, or other complications compared with the control group. However, the length of time recorded from measuring 0.3 vol\% sevoflurane in patient expiration to patient awakening $(\mathrm{P}=0.006)$ was longer in the esmolol group than in the control group, while there were no significant differences with the ketamine group. Whether the administration of esmolol actually elongated the time to awakening or whether it was just a technical problem is not certain and will require further research. In addition, when esmolol was administered, the pain score (VAS) was lowered for 15 minutes after surgery and the fentanyl requirement was reduced, effects similar to those shown with ketamine. In our study, the duration of lowered pain score (VAS) and reduced fentanyl requirement due to esmolol was shorter compared with precedent studies $[10,12]$. This result can be attributed to the fact that the pain characteristics were different in this study compared with precedent studies, as remifentanil was continuously infused during surgery and all three groups were given fentanyl as a bolus before the end of surgery; thus, active pain control was performed in the control group, as well. The mechanism by which esmolol lowers postoperative pain score (VAS) and reduces fentanyl requirement is not clear. In functional magnetic resonance imaging studies in humans, hippocampal activation has been observed during emotional distress [23]. This hippocampal activation results from the activity of stress-related factors, including norepinephrine, which enhances the excitability of hippocampal principal neurons via an interaction with hippocampal NMDA subtype glutamate receptors [24]. The hippocampus is considered to have a major role in nociception, and this role is predicted to involve the NMDA receptor [22]. It is possible that hippocampal $\beta$-adrenergic receptor activation plays a major role in the nociceptive process [22]. If this is the case, then the blockade of such receptors can blunt the $\beta$-adrenergic activation of the nociceptive process. Therefore, it has been speculated that the nociceptive sense can be attenuated in this way [22]. In autoradiographic studies of the rat hippocampus, both $\beta_{1}$ - and $\beta_{2}$ adrenergic receptor expression has been reported [25]. Esmolol is known to be unable to pass through the blood-brain barrier; thus, rather than working directly on the brain, it is expected to work by blocking the $\beta$-adrenoceptor within the brainstem and reducing neuronal inflow into the central nervous system [26]. As another possible mechanism to explain the reduction in postoperative fentanyl requirement, esmolol can reduce the metabolism of other medications as well as its own by reducing hepatic blood flow [27]. One study reported that propranolol, a $\beta$-adrenergic blocking agent, reduced cardiac output and caused a change in organ blood flow distribution, leading to a reduction in fentanyl requirement by changing the pharmacokinetics of fentanyl [28]. Likewise, in the present study, it is thought that esmolol administered during surgery may have affected the pharmacokinetics of fentanyl or ketorolac administered before the end of surgery.

There are several limitations to this study. First, the doctor who participated in anesthesia induction was not blinded to the 
administered agent. However, as this doctor did not participate in the postoperative evaluation, there is no possibility that this influenced the measurement of pain score (VAS) or fentanyl requirements. Second, as the postoperative pain score (VAS) assessment did not differentiate between incisional pain, visceral deep pain, and shoulder referred pain, it is not clear what kind of pain patients were experiencing. However, because pain at the operated area was included in the questionnaire, the evaluation is considered to represent incisional pain. Third, we adjusted the concentration of sevoflurane to maintain intraoperative BIS value within $40-60$, but the effect of different inhalation concen- trations on rapid postoperative pain after remifentanil-based anesthesia is not known. However, because intraoperative opioids and $\beta$-blockers are known to have no effect on BIS $[29,30]$, the difference in inhalation concentration of sevoflurane is thought to have had a marginal influence on postoperative pain in these three groups, which had similar BIS index values.

In conclusion, intraoperative esmolol infusion during laparoscopic cholecystectomy with remifentanil-based anesthesia can reduce pain score (VAS) and fentanyl requirements in the immediate postoperative period, and this effect is similar to that of intraoperative ketamine infusion.

\section{References}

1. Hong BH, Lee WY, Kim YH, Yoon SH, Lee WH. Effects of intraoperative low dose ketamine on remifentanil-induced hyperalgesia in gynecologic surgery with sevoflurane anesthesia. Korean J Anesthesiol 2011; 61: 238-43.

2. Guignard B, Bossard AE, Coste C, Sessler DI, Lebrault C, Alfonsi P, et al. Acute opioid tolerance: intraoperative remifentanil increases postoperative pain and morphine requirement. Anesthesiology 2000; 93: 409-17.

3. Derrode N, Lebrun F, Levron JC, Chauvin M, Debaene B. Influence of peroperative opioid on postoperative pain after major abdominal surgery: Sufentanil TCI versus remifentanil TCI. A randomized, controlled study. Br J Anaesth 2003; 91: 842-9.

4. Wilder-Smith OH, Arendt-Nielsen L. Postoperative hyperalgesia: its clinical importance and relevance. Anesthesiology 2006; 104: 601-7.

5. Chizh BA. Low dose ketamine: a therapeutic and research tool to explore N-methyl-D-aspartate (NMDA) receptor-mediated plasticity in pain pathways. J Psychopharmacol 2007; 21: 259-71.

6. Joly V, Richebe P, Guignard B, Fletcher D, Maurette P, Sessler DI, et al. Remifentanil-induced postoperative hyperalgesia and its prevention with small-dose ketamine. Anesthesiology 2005; 103: 147-55.

7. Gu X, Wu X, Liu Y, Cui S, Ma Z. Tyrosine phosphorylation of the N-Methyl-D-Aspartate receptor 2B subunit in spinal cord contributes to remifentanil-induced postoperative hyperalgesia: the preventive effect of ketamine. Mol Pain 2009; 5: 76.

8. Zaugg M, Tagliente T, Lucchinetti E, Jacobs E, Krol M, Bodian C, et al. Beneficial effects from beta-adrenergic blockade in elderly patients undergoing noncardiac surgery. Anesthesiology 1999; 91: 1674-86.

9. Johansen JW, Flaishon R, Sebel PS. Esmolol reduces anesthetic requirement for skin incision during propofol/nitrous oxide/morphine anesthesia. Anesthesiology 1997; 86: 364-71.

10. Chia YY, Chan MH, Ko NH, Liu K. Role of beta-blockade in anaesthesia and postoperative pain management after hysterectomy. Br J Anaesth 2004; 93: 799-805.

11. White PF, Wang B, Tang J, Wender RH, Naruse R, Sloninsky A. The effect of intraoperative use of esmolol and nicardipine on recovery after ambulatory surgery. Anesth Analg 2003; 97: 1633-8.

12. López-Álvarez S, Mayo-Moldes M, Zaballos M, Iglesias BG, Blanco-Dávila R. Esmolol versus ketamine-remifentanil combination for early postoperative analgesia after laparoscopic cholecystectomy: a randomized controlled trial. Can J Anaesth 2012; 59: 442-8.

13. Hang LH, Shao DH, Gu YP. The ED50 and ED95 of ketamine for prevention of postoperative hyperalgesia after remifentanil-based anaesthesia in patients undergoing laparoscopic cholecystectomy. Swiss Med Wkly 2011; 141: w13195.

14. Bisgaard T. Analgesic treatment after laparoscopic cholecystectomy: a critical assessment of the evidence. Anesthesiology 2006; $104: 835-46$.

15. Song D, White PF. Remifentanil as an adjuvant during desflurane anesthesia facilitates early recovery after ambulatory surgery. J Clin Anesth 1999; 11: 364-7.

16. Song D, Whitten CW, White PF. Remifentanil infusion facilitates early recovery for obese outpatients undergoing laparoscopic cholecystectomy. Anesth Analg 2000; 90: 1111-3.

17. Hood DD, Curry R, Eisenach JC. Intravenous remifentanil produces withdrawal hyperalgesia in volunteers with capsaicin-induced hyperalgesia. Anesth Analg 2003; 97: 810-5.

18. Luginbühl M, Gerber A, Schnider TW, Petersen-Felix S, Arendt-Nielsen L, Curatolo M. Modulation of remifentanil-induced analgesia, hyperalgesia, and tolerance by small-dose ketamine in humans. Anesth Analg 2003; 96: 726-32.

19. Angst MS, Clark JD. Opioid-induced hyperalgesia: a qualitative systematic review. Anesthesiology 2006; 104: 570-87.

20. Koppert W, Sittl R, Scheuber K, Alsheimer M, Schmelz M, Schüttler J. Differential modulation of remifentanil-induced analgesia and postinfusion hyperalgesia by S-ketamine and clonidine in humans. Anesthesiology 2003; 99: 152-9.

21. Davidson EM, Doursout MF, Szmuk P, Chelly JE. Antinociceptive and cardiovascular properties of esmolol following formalin injection in rats. Can J Anaesth 2001; 48: 59-64. 
22. Collard V, Mistraletti G, Taqi A, Asenjo JF, Feldman LS, Fried GM, et al. Intraoperative esmolol infusion in the absence of opioids spares postoperative fentanyl in patients undergoing ambulatory laparoscopic cholecystectomy. Anesth Analg 2007; 105: 1255-62.

23. Sinha R, Lacadie C, Skudlarski P, Wexler BE. Neural circuits underlying emotional distress in humans. Ann N Y Acad Sci 2004; $1032: 254-7$.

24. Sarvey JM, Burgard EC, Decker G. Long-term potentiation: studies in the hippocampal slice. J Neurosci Methods 1989; 28 : 109-24.

25. Booze RM, Crisostomo EA, Davis JN. Beta-adrenergic receptors in the hippocampal and retrohippocampal regions of rats and guinea pigs: Autoradiographic and immunohistochemical studies. Synapse 1993; 13: 206-14.

26. Sum CY, Yacobi A, Kartzinel R, Stampfli H, Davis CS, Lai CM. Kinetics of esmolol, an ultra-short-acting beta blocker, and of its major metabolite. Clin Pharmacol Ther 1983; 34: 427-34.

27. Wood AJ, Feely J. Pharmacokinetic drug interactions with propranolol. Clinical Pharmacokinetics 1983; 8: 253-62.

28. Avram MJ, Krejcie TC, Henthorn TK, Niemann CU. Beta-adrenergic blockade affects initial drug distribution due to decreased cardiac output and altered blood flow distribution. J Pharmacol Exp Ther 2004; 311: 617-24.

29. Kalkman CJ, Drummond JC. Monitors of depth of anesthesia, quo vadis? Anesthesiology 2002; 96: 784-7.

30. Yang H, Fayad A. Are beta-blockers anesthestics? Can J Anaesth 2003; 50: 627-30. 